\title{
Em fronteiras: a proposta do curriculum trivium no contexto de aulas de Português para haitianos
}

\author{
Marília Prado 1 (®) \\ USP, Faculdade de Educação, São Paulo, SP, Brasil \\ Cristiane Coppe de Oliveira ${ }^{2}$ \\ UFU, Instituto de Ciências Exatas e Naturais do Pontal, Ituiutaba, MG, Brasil
}

\begin{abstract}
Resumo
Este artigo é um recorte de um projeto de pesquisa de doutorado desenvolvido no Programa de PósGraduação em Educação da Universidade de São Paulo (FEUSP). Tem como objetivo apresentar as primeiras aproximações da investigação, com estudantes haitianos em um projeto de aprendizagem de português. Por meio da observação participante nas aulas, a primeira etapa do projeto se deu em um Centro Integrado de Educação de Jovens e Adultos (CIEJA) na cidade de São Paulo. Levantamos elementos pertencentes as fronteiras que atravessam a diáspora haitiana dos estudantes participantes das aulas de português. Considerando as teorizações do Programa Etnomatemática, o conceito de tema gerador de Freire e as possibilidades de uma proposta pautada no conhecimento trivium (materacia, literacia e tecnoracia) e, aproximando-nos da realidade dos estudantes, identificamos o tema gerador Trabalho, como um elemento que pode mobilizar saberes que o cercam no cotidiano. Esperamos que a história de vida dos estudantes haitianos e os elementos que os limitam sócioculturalmente possam, além de trazer conhecimentos escolares, colaborar para retirá-los das fronteiras da invisibilidade e do racismo.
\end{abstract}

Palavras-chave: Fronteiras; Haitianos; Programa Etnomatemática; Conhecimento Trivium.

\section{In Boundaries: the proposal of the trivium curriculum in the context of Portuguese for Haitians}

\begin{abstract}
This article is an clipping of a doctoral research project, developed in the Graduate Program in Education of the University of São Paulo (FEUSP). It aims to present the first approaches of the research, with Haitian students in a learning project of Portuguese. Through participant observation in the classes, the first stage of the project took place in an Centro Integrado de Educação de Jovens e Adultos (CIEJA) in the city of São Paulo. We raise elements belonging to the borders that cross the Haitian diaspora of the students participating in the Portuguese. Considering the theorizations of the

Submetido em: 26/06/2021 Aceito em: 18/08/2021 Publicado em: 03/09/2021

\footnotetext{
${ }^{1}$ Doutoranda em Educação pela Universidade de São Paulo. E-mail: mariliap@usp.br.

2 Doutora em Educação pela Universidade de São Paulo. Professora do Programa de Pós-Graduação em Ensino de Ciências e Matemática da Universidade Federal de Uberlândia. Endereço para correspondência: Avenida 20, Bairro Tupã, Ituiutaba, MG, CEP: 38300000. E-mail: coppedeoliveira@gmail.com.
} 
Ethnomathematics Program, Freire's concept of the theme and the possibilities of a proposal based on trivium knowledge (materacy, literacy and tecnoracy) and approaching the reality of the students, we identified the theme generator Work, as an element that can mobilize knowledge that surrounds it in daily life. We hope that the life history of Haitian students and the elements that limit them socioculturally can, in addition to bringing school knowledge, to remove them from the borders of invisibility and racism.

Keywords: Boundaries; Haitians; Ethnomathematics Program; Trivium knowledge.

\section{Em las fronteras: la propuesta del currículo trivium en el contexto del portugués para los haitianos}

\section{Resumen}

Este artículo forma parte de un proyecto de investigación doctoral desarrollado en el Programa de Posgrado en Educación de la Universidad de Sao Paulo (FEUSP). Su objetivo es presentar los primeros enfoques de la investigación, con estudiantes haitianos en un proyecto de aprendizaje de portugués. A través de la observación de los participantes en las clases, la primera etapa del proyecto tuvo lugar en un Centro Integrado de Educación juvenil y de adultos (CIEJA) en la ciudad de Sao Paulo. Levantamos elementos pertenecientes a las fronteras que cruzan la diáspora haitiana de los estudiantes que participan de las clases de portugues. Teniendo en cuenta las teorizaciones del Programa Etnomatemática, el concepto de Freire del tema del generador y las posibilidades de una propuesta basada en el conocimiento trivium (materacy, literacy y tecnoracy) y, acercándose a la realidad de los estudiantes, identificamos el generador temático Trabajo, como un elemento que puede movilizar el conocimiento que los rodea en la vida cotidiana. Esperamos que la historia de la vida de los estudiantes haitianos y los elementos que los limitan socioculturalmente puedan, además de aportar conocimientos escolares, colaborar para sacarlos de las fronteras de la invisibilidad y el racismo.

Palabras clave: Fronteras; Haitianos; Programa Etnomatemáticas; Conocimiento trivium.

\section{Introdução}

Atualmente as migrações afetam quase todas as regiões do mundo. Seja por crises políticas, econômicas ou ambientais, milhões de pessoas saem de seus países de origem em busca de melhores condições de vida. De acordo com Wenden (2016), ao redor do mundo, há uma tendência de regionalização dos fluxos migratórios em que se observa uma complementaridade entre zonas de partida e de acolhida pela proximidade geográfica, por vínculos históricos, linguísticos e culturais, pela construção de redes transnacionais construídas pelos migrantes e pelo encontro de fatores de oferta e procura de mão de obra.

O Brasil, em especial a cidade de São Paulo, há muito tempo tem sido destino de imigrantes provenientes de diversos países. No início do século XX, o principal movimento migratório seguia o curso Norte-Sul, quando a cidade recebeu milhões de pessoas vindas da Itália, Japão e Portugal, por exemplo. No entanto, desde o início dos anos 2000, uma nova dinâmica de migrações, devido ao 
fenômeno da regionalização dos deslocamentos, tem sido observada. A cidade de São Paulo passou a ser destino de migrantes originários de países da América do Sul e da América Central.

Em relação à pessoa que migra, devemos nos lembrar que não se trata apenas de deslocar-se de um país para outro. Segundo Seixas (2016), qualquer que seja o motivo da migração - voluntária ou forçada -, esse processo causa uma crise de identidade com múltiplas dimensões.

O migrante constata que não pertence inteiramente à cultura do lugar para onde migra. Em vários aspectos o migrante é "diferente" das pessoas que ali estão e é também "igual" a elas. [...] Disto resulta que o migrante comporá imaginário (uma representação) que implicará na reformulação de sua própria identidade cultural, que será a síntese possível, híbrida, de pelos menos dois sistemas simbólicos culturais. (SEIXAS, 2016, p.14)

Nesse processo, então, conhecer uma nova realidade social e cultural traz a necessidade de conhecer novas linguagens, novos significados, novas percepções e novas interpretações para lidar com situações de seu cotidiano. Paras as pessoas que migram, há um processo de negociação com as novas culturas, "sem simplesmente serem assimiladas por elas e sem perder completamente suas identidades" (HALL, 2015, p.52).

Diante dessa necessidade, os imigrantes que chegam atualmente em São Paulo buscam, em princípio, aprender a Língua Portuguesa e, por meio da educação, ter acesso a melhores condições para se estabelecer no novo país, mas a barreira do idioma não é a única que enfrentam. Ao chegar no Brasil, depois de ter atravessado as fronteiras entre países, o imigrante, principalmente vindo de países periféricos, permanecem em fronteiras: as fronteiras urbanas, projetadas sobretudo para diferenciar indivíduos em termos de classe social.

Nessa perspectiva, o presente artigo traz um recorte de uma pesquisa de doutorado, em andamento, que busca articular ideias do programa etnomatemática em um cenário educacional para imigrantes. O contexto em questão é o Centro Integrado de Educação de Jovens e Adultos (CIEJA), localizado no bairro de Perus, na cidade de São Paulo. Entre brasileiros e imigrantes, a escola atende cerca de 1500 estudantes adultos, dos quais 800 são haitianos que frequentam as aulas por diferentes razões: alguns não foram alfabetizados no Haiti, outros concluíram o ensino básico no Haiti, mas não têm a documentação que comprove a escolaridade; no entanto, a maioria vai para a escola apenas para aprender português.

Assim, procuramos investigar, na perspectiva do Programa Etnomatemática, em primeiro lugar, quais são as fronteiras que atravessam a trajetória de imigrantes haitianos em São Paulo; e, posteriormente, como se dá a aquisição e o desenvolvimento do conhecimento trivium - literacia, materacia e tecnoraria (D’AMBROSIO, 2016) - pelos estudantes haitianos do CIEJA Perus. 
Tratamos aqui da primeira etapa da pesquisa, que tinha como objetivo conhecer o contexto, a realidade dos estudantes haitianos, e agrupar elementos socioculturais. Para isso, utilizamos, como metodologia, a observação participante nas aulas de um projeto de Português para haitianos.

Como parte desta primeira etapa, discutimos a trajetória do imigrante haitiano com base em estudos que buscam ampliar o conhecimento sobre fluxos migratórios no Brasil.

Em seguida, exploramos os diferentes entendimentos de fronteiras que embasam a nossa concepção sobre o termo. Considerando a fronteira como lugar de distinção e exclusão social, apoiamo-nos nos estudos de Santos (2010) sobre as linhas abissais e sobre o "reconhecimento da pluralidade de conhecimentos heterogêneos" (p.53). O autor propõe o rompimento com as formas ocidentais modernas que orientam pensamento e ação, para dar condição ao pensamento pós-abissal, situando a perspectiva epistemológica "do outro lado da linha".

Para uma proposta política e educacional que não reproduza a linha abissal, temos fundamentado nossa pesquisa nas ideias de Paulo Freire $(2011,2019)$ e do Programa Etnomatemática de D’Ambrósio (2017), principalmente porque os dois autores mostram, em todas as suas obras, a preocupação com a compreensão crítica da realidade, com respeito à cultura do indivíduo.

\section{Do Haiti para o Brasil: a diáspora haitiana}

Pessoas migram por diferentes motivos - políticos, econômicos, ambientais -, seus países de origem e destino também são diferentes. Partindo do pressuposto de que buscamos, inicialmente, conhecer a realidade do imigrante haitiano, consideramos essencial a compreensão das características da migração haitiana.

O Haiti foi o primeiro Estado do mundo a surgir de uma insurreição de escravos. Também foi o primeiro país a abolir a escravatura e o segundo na América a proclamar a independência. Foi justamente o que determinou seu destino.

A Revolução do Haiti durou cerca de 30 anos (1791 - 1825). Segundo Seguy (2014), após 1825, o Estado haitiano emprestou, de banqueiros franceses, 30 milhões de francos, na tentativa de conseguir liquidar parte da chamada "dívida de Independência". Assim, assumiu uma dupla dívida, que é considerada "depois da colonização, a principal raiz sócio-histórica que mergulha as classes laboriosas haitianas na precariedade e reiniciou as preparativas para uma catástrofe humana como a de 2010" (SEGUY, 2014, p. 160).

Nesse sentido, destacamos,

[...] Não há maldição ancestral ou religiosa alguma ligada ao destino do povo negro haitiano, e sim uma intervenção colonizadora histórica e consciente por parte das grandes potências capitalistas para sufocar e impedir a expansão livre e independente 
daquela sofrida, mas nobre, nação, para aproveitar-se da força de trabalho extraída da miséria a que foi reduzido o Haiti. (RIBEIRO, 2010, p. 7)

Uma história complexa, marcada por injustiças, conflitos violentos, dívidas e invasões, deixou o país em permanente estado de vulnerabilidade social, econômica e política, colocando-o entre os mais pobres do mundo.

Após o terremoto de 12 de janeiro de 2010 - a catástrofe a que Seguy (2014) se refere acima -, a situação do Haiti piorou ainda mais. Cerca de 300 mil pessoas morreram e mais de um milhão ficaram desabrigadas.

De acordo com o Diagnóstico Regional sobre Migração Haitiana ${ }^{3}$ (2017), a República Dominicana, país vizinho ao Haiti, foi um dos primeiros a se solidarizar após o desastre, abrindo a fronteira e possibilitando a abertura de canais de ajuda imediata em acampamentos próximos à fronteira, com a ajuda da ONU.

Logo, países da América do Sul como Venezuela, Chile e Equador ofereceram estratégias de regularização de haitianos que se encontravam em seus territórios, bem como facilitaram a reunificação familiar com os imigrantes haitianos residentes. No entanto, tais medidas não foram formalizadas naquele momento, exceto pelo Equador.

Alguns meses depois, inicia-se um novo movimento de migração: os haitianos passam a ter o Brasil como principal destino. Os motivos para a escolha do Brasil como destino de migração, segundo o Diagnóstico Regional sobre Migração Haitiana (2017), não eram claros. De um lado, coloca-se o imaginário construído a respeitos das opções de trabalho, uma vez que, na época, o Brasil aparecia como a nova potência mundial emergente. De outro, considera-se que a presença das tropas brasileiras da Missão das Nações Unidas para a estabilização do Haiti (MINUSTAH) ${ }^{4}$ pode ter contribuído para a ideia do Brasil como um país de oportunidades.

Em alguns casos, o Brasil era considerado um país de passagem, cujo destino final era a Guiana Francesa (para chegar à França), Estados Unidos ou Canadá. Nesse caso, conforme apontam Fernandes e Farias (2016), um dos fatores a se considerar é a presença de redes de tráfico que recrutavam cidadãos no Haiti com a promessa de trabalho e estudo em países da América Latina, nos Estados Unidos e Europa. Porém, essas redes dirigiam suas vítimas ao Equador, onde as abandonavam.

Esses autores apontam que, no início do fluxo migratório (2010-2012), a trajetória mais comum se dava partindo de Porto Príncipe ou da República Dominicana, por via aérea, passando pela

\footnotetext{
${ }^{3}$ Estudo desenvolvido pelo Instituto de Políticas Públicas em Direitos Humanos do Mercosul (IPPDH) e pela Organização Internacional para as Migrações (OIM).

${ }^{4}$ Criada por Resolução pelo Conselho de Segurança da ONU, permaneceu no Haiti de 2004 a 2017.
} 
Cidade do Panamá. De lá, alguns iam para Quito ou para Lima, de onde - por trajeto terrestre ou fluvial - chegavam à fronteira com o Brasil, onde ingressavam de forma irregular, no estado do Amazonas ou do Acre.

Fernandes e Farias (2016) ressaltam que, em 2010, Argentina, Chile, Equador e Peru não exigiam visto para entrada de haitianos em seu território, mas mesmo assim, esses países não se tornaram destino final da migração haitiana em grande volume. A entrada de haitianos em maior número pode "indicar que esta migração não é gestada unicamente pelas facilidades de entrada no país, [...], mas é determinada pela intenção de chegar e de se estabelecer na região de destino" (idem, p.104).

No final de 2011, já havia a presença de cerca de 4000 haitianos no Brasil e, naquele momento, iniciou-se o que poderia ser chamada de crise migratória nas fronteiras: "os recémchegados se somam a algumas centenas que já se encontravam em cada cidade à espera de regularização e, em muitos casos, em situação precária” (IPPDH; OIM, 2017, p.34, tradução livre). Percebeu-se, assim, a necessidade de instrumentos normativos e da discussão sobre uma nova lei migratória. A partir disso, se instaura a Resolução Normativa 97 (RN-97), de janeiro de 2012, que determinava a concessão do visto permanente, por razões humanitárias, para o imigrante haitiano.

Tal resolução autorizava a emissão de apenas 100 vistos mensais pela Embaixada do Brasil em Porto Príncipe. Em 2013, prorrogada por meio da Resolução Normativa 102 (RN-102), passou a permitir a emissão ilimitada de vistos. Mesmo assim, a imigração irregular por via terrestre não diminuiu.

De acordo com o documento do IPPDH e OIM (2017), dois furacões atingiram a região do Haiti, em 2012. Em 2013, uma crise política e diplomática entre o Haiti e a República Dominicana retirou a nacionalidade de 200000 pessoas cujos pais eram indocumentados, afetando principalmente os descendentes de haitianos. Esses dois fatos contribuíram para a intensificação da migração haitiana.

O período entre 2014 e 2016 marca o que pode ser identificado como uma segunda fase migratória, cujas principais características são: reunificação/integração familiar; feminização da migração haitiana; diversificação da procedência social, econômica e geográfica dos novos imigrantes. Vemos, assim, o processo de consolidação da migração haitiana para a América do Sul e, também, uma nova mobilidade de alguns migrantes para novos destinos intrarregionais.

De acordo com Fernandes e Farias (2016), em 2015, um acordo entre o Itamaraty e a OIM ampliou a capacidade de emissão de visto pelo Consulado do Brasil em Porto Príncipe. Tal acordo permitia a expedição de 500 vistos por semana. 
A Tabela 1, abaixo, mostra a quantidade de migrantes haitianos em situação regular em cada país da América do Sul.

Tabela 1- Quantidade estimada de migrantes haitianos e proporção relativa por país na América do Sul.

\begin{tabular}{|c|r|r|c|}
\hline País & Quantidade & Período & \% \\
\hline Argentina & 1165 & $2011-2015$ & $<1 \%$ \\
\hline Bolívia & 905 & $2011-2015$ & $<1 \%$ \\
\hline Brasil & 67226 & $2010-2016$ & $5,5 \%$ \\
\hline Chile & 17849 & $2011-2015$ & $2,8 \%$ \\
\hline Colômbia & 1375 & $2010-2016$ & $<1 \%$ \\
\hline Equador & 776 & $2011-2014$ & $<1 \%$ \\
\hline Paraguai & 15 & 2016 & $<1 \%$ \\
\hline Peru & 56 & 2016 & $<1 \%$ \\
\hline Uruguai & 2 & $2012-2016$ & $<1 \%$ \\
\hline Venezuela & 6509 & 2016 & $<1 \%$ \\
\hline
\end{tabular}

Fonte: IPPDH; OIM. Diagnóstico Regional sobre migração haitiana. 2017

Pela tabela, vemos que o Brasil foi o país que mais recebeu imigrantes haitianos nos últimos anos, mesmo com todas as dificuldades para obtenção do visto.

Para se candidatar à permissão, o postulante deve ter passaporte em dia, ser residente no Haiti (o que deve ser comprovado por atestado de residência) e apresentar atestado de bons antecedentes. Com todos os documentos em mãos, deve ainda pagar US\$ 200 para a emissão do visto (FERNANDES; FARIA, 2016, p.102).

Segundo dados da Polícia Federal de novembro de 2019, 118323 registros de haitianos permanecem ativos no Brasil.

De acordo com o que foi exposto acima, foi possível ter uma visão geral a respeito do Haiti e da imigração haitiana, abordando alguns elementos de sua história e das situações que resultaram na diáspora haitiana.

O Brasil, em particular, teve um importante papel no acolhimento desses imigrantes. No entanto, devemos considerar, conforme destacam Fernandes e Farias (2016): de um lado, o movimento migratório deu início “a um processo de discussão da legislação migratória, introduzindo nos debates a visão do respeito aos direitos humanos dos imigrantes" (idem, p.104). Por outro lado, a percepção da presença dos haitianos no Brasil foi vista com desconfiança pela sociedade. Essa 
desconfiança foi reforçada por alguns órgãos da imprensa, que comparavam a imigração haitiana com uma "invasão".

De acordo com o que foi discutido, podemos entender que, no Brasil,

[...] muitos haitianos encontram dificuldades de adaptação diversas e têm que lidar no cotidiano com o preconceito, frequentemente explícito, de parcela da população brasileira. Preconceito reforçado, pois resulta da soma da estranheza aos estrangeiros em geral (sobretudo não europeus) com a discriminação racial, adicionado à crise econômica que aumenta o desemprego. (MOREL, 2017, p. 19)

É preciso lembrar que, tanto os haitianos mais pobres, quanto os profissionais qualificados e com formação universitária lidam com situações semelhantes. Frente à urgência de suprir necessidades básicas como alimentação e moradia, eles são direcionados a "setores altamente marcados pela precarização do trabalho, como a indústria têxtil, de abate de carnes, construção civil, serviços domésticos, entre outros" (VILLEN, 2016, p. 47).

Embora, segundo o relatório da OBMigra (2019), o Haiti ocupe as primeiras posições em número de imigrantes no mercado de trabalho formal brasileiro, o imigrante haitiano é o que tem o menor rendimento médio mensal, 1306 reais.

Além de todos os obstáculos que o povo negro haitiano enfrenta no deslocamento, ele não só vivencia a experiência de passagem por fronteiras políticas (de um país para outro), mas também experiencia outros tipos de fronteiras, que abordaremos a seguir.

\section{Fronteiras, etnomatemática e currículo}

As experiências migratórias implicam em fronteiras. Essas fronteiras não são apenas as conhecidas fronteiras políticas, podem ser entendidas de maneiras diferentes.

Hannerz (1997) associa a ideia de fronteira a limites de cultura, atribuindo ao conceito as características de descontinuidade e obstáculo. Para ele, trata-se de "uma linha clara de demarcação, em relação à qual uma coisa ou está dentro ou está fora" (HANNERZ, 1997, p.15). Por um lado, o autor considera que "estar dentro" ou "estar fora" remete à ideia de pertencimento. Da perspectiva da identidade social, "o limite estaria claramente demarcado, envolvendo, na maior parte das vezes, formas culturais selecionadas, dicotomicamente distribuídas e compreendidas como emblemáticas da condição de membro do grupo" (idem).

Por outro lado, no entanto, ele considera que os fluxos culturais modelam e dissolvem os limites, uma vez que, 
À medida que a cultura se move por entre correntes mais específicas, como o fluxo migratório, o fluxo de mercadorias e o fluxo da mídia, ou combinações entre estes, introduz toda uma gama de modalidades perceptivas e comunicativas que provavelmente diferem muito na maneira de fixar seus próprios limites; ou seja, em suas distribuições descontínuas entre pessoas e pelas relações. (HANNERZ, 1997, p.18)

Desse modo, ele observa que, metaforicamente, "limite" pode ser combinado à ideia de "fronteira" ou "zona fronteiriça", entendendo que os últimos termos "não implicam linhas nítidas e sim regiões, nas quais uma coisa gradualmente se transforma em outra, onde há indistinção, ambiguidade e incerteza" (idem, p.20).

De outra perspectiva, entendemos que Martins (2019) contribui para a discussão sobre fronteiras, pois nos leva a refletir a respeito do lugar onde a pesquisa ocorre, a respeito do encontro com o outro.

O que há de sociologicamente mais relevante para caracterizar e definir a fronteira no Brasil é, justamente, a situação de conflito social. [...] Na minha interpretação, nesse conflito, a fronteira é essencialmente o lugar da alteridade. É isso que faz dela uma realidade singular. À primeira vista é o lugar do encontro dos que por diferentes razões são diferentes entre si, como os índios de um lado e os ditos civilizados de outro; como os grandes proprietários de terra, de um lado, e os camponeses pobres, de outro. Mas o conflito faz com que a fronteira seja essencialmente, a um só tempo, um lugar de descoberta do outro e de desencontro. Não só o desencontro e o conflito decorrentes das diferentes concepções de vida e visões de mundo de cada um desses grupos humanos. O desencontro da fronteira é o desencontro de temporalidades históricas, pois cada um desses grupos está situado diversamente no tempo da história. (MARTINS, 2019, p.133, grifos do autor)

Balibar (2002) discute, mais especificamente, sobre as fronteiras vividas por imigrantes e refugiados, antecipando que responder "o que é uma fronteira?" não é uma tarefa simples. Para o autor, "não podemos atribuir à fronteira uma essência que seria válida em todos os tempos, para toda escala física e todo período de tempo, e na qual seria incluída ao mesmo tempo toda experiência individual e coletiva" (BALIBAR, 2002, p. 75, tradução livre).

Ao argumentar sobre os significados de fronteira, Balibar (2002) recorre a três características: a sobredeterminação - historicamente, as fronteiras motivadas por demarcações culturais ou interesses econômicos; a natureza polissêmica - se referindo ao fato de que fronteiras não existem da mesma maneira para indivíduos de diferentes classes sociais; e a heterogeneidade - que considera que as diversas funções de demarcação e territorialização, efetivadas pelas fronteira, evidenciam a distinção social e distinção de direitos, por exemplo. 
Com essas características, a fronteira, para Balibar (2002), não é apenas um obstáculo muito difícil de superar, mas o lugar onde o imigrante de um país pobre reside: "uma casa para viver uma vida que é um esperar-para-viver, uma não-vida" (idem, p.83, tradução livre).

De maneira geral, vemos que as fronteiras se estabelecem como uma região de separação. Particularmente, conforme aponta Balibar (2002), atualmente, fronteiras são projetadas

não apenas para dar aos indivíduos de diferentes classes sociais diferentes experiências da lei, da administração civil, de direitos policiais e elementares, tais como a liberdade de circulação e a liberdade de empreendimento, mas ativamente para diferenciar entre indivíduos em termos de classe social (BALIBAR, 2002, p.81).

Desse modo, nos aproximamos de Mesquita (2014), ao reconhecer aqui, as fronteiras urbanas, entendidas, vividas e sentidas, como um substrato material da nossa sociedade urbana contemporânea e trabalhadas enquanto um fenômeno econômico.

Podemos considerar, então, que imigrantes haitianos atravessam as fronteiras de um país até outro e permanecem nas fronteiras culturais, por exemplo, quando encontram dificuldades com o idioma português; quando percebem as diferenças entre eles e os moradores locais; no confronto com o repertório identitário do outro. E também, nas fronteiras sociais, quando se veem, por exemplo, "trabalhando e vivendo numa periferia do capitalismo" (VILLEN, 2016), em condições precarizadas. Nessa diferença cultural e social que é imposta, reconhecemos o que Santos (2010) chama de pensamento abissal: um sistema de distinções visíveis e invisíveis, em que as invisíveis são estabelecidas através de linhas radicais que dividem a realidade social entre o universo "deste lado da linha" e o universo "do outro lado da linha". "As distinções intensamente visíveis que estruturam a realidade social deste lado da linha baseiam-se na invisibilidade das distinções entre este e o outro lado da linha" (SANTOS, 2010, p.33), originando, assim, práticas de exclusão.

Em relação ao campo do conhecimento, o autor considera que a linha abissal concede à ciência moderna o monopólio da distinção entre o que é verdadeiro e o que é falso e tende a eliminar qualquer realidade que esteja "do outro lado". Com isso, o conhecimento produzido do outro lado é visto como crença, opinião, magia, idolatria ou entendimentos intuitivos e subjetivos, como não conhecimento. No entanto, Santos (2010), reconhece a existência de uma pluralidade de conhecimentos heterogêneos e, por isso, propõe o pensamento pós-abissal como "ruptura radical com as formas ocidentais modernas de pensamento e ação" (p.53).

Tendo isso em mente e buscando instrumentos conceituais e políticos que, de acordo com Santos (2010), não reproduzam as linhas abissais, encontramos na obra de Paulo Freire e no Programa Etnomatemática a base teórica de nossa pesquisa. 
Em toda a obra de Paulo Freire vemos seu posicionamento político contra a opressão e em favor da libertação. Libertação essa que se pauta na práxis da busca e no conhecimento e reconhecimento da necessidade de lutar por ela.

Na proposta da pedagogia do oprimido, ele destaca que é

aquela que tem de ser forjada com ele e não para ele, enquanto homens ou povos, na luta incessante de recuperação de sua humanidade. Pedagogia que faça da opressão e de suas causas objeto da reflexão dos oprimidos, de que resultará o seu engajamento necessário na luta por sua libertação, em que esta pedagogia se fará e refará (FREIRE, 2019, p.43).

Para o autor, quando os oprimidos são objetos no processo da aprendizagem da leitura e escrita, a eles se impõe "a recepção passiva de um conhecimento empacotado" (FREIRE, 2011). O autor aponta que,

o aprendizado da escrita e da leitura, como um ato criador, envolve, aqui, necessariamente, a compreensão crítica da realidade. O conhecimento do conhecimento anterior, a que os alfabetizandos chegam ao analisar a sua prática no contexto social, thes abre a possibilidade a um novo conhecimento: conhecimento novo, que indo mais além dos limites do anterior, desvela a razão de ser dos fatos, desmitificando, assim, as falsas interpretações dos mesmos. Agora, nenhuma separação entre pensamento-linguagem e realidade objetiva, daí que a leitura de um texto demande a 'leitura' do contexto social a que se refere. (idem, p.39).

Com base nisso, Freire (2019) considera que a organização do conteúdo programático da educação "será a partir da situação presente, existencial, concreta, refletindo o conjunto e aspirações do povo" (p.119). Para o autor, isso se dá através da investigação de um conjunto de "temas geradores".

Esta investigação implica, necessariamente, uma metodologia que não pode contradizer a dialogicidade da educação libertadora. Daí que seja igualmente dialógica. Daí que, conscientizadora também, proporcione, ao mesmo tempo, a apreensão dos "temas geradores" e a tomada de consciência dos indivíduos em torno dos mesmos (FREIRE, 2019, p.121)

Segundo Vergani (2007), as obras de Paulo Freire e de Ubiratan D’Ambrósio se relacionam pela "mesma consciência crítica, o mesmo carisma criador de vias alternativas, o mesmo profundo desejo de justiça autenticamente abrangente" (p. 24), como podemos observar ao conhecer o Programa Etnomatemática.

De acordo com D’Ambrósio (2016, 2017), idealizador do termo e do Programa Etnomatemática, diferentes culturas desenvolvem sistemas de conhecimento. Esses sistemas são entendidos como formas, estilos e técnicas de fazer, explicar, compreender e ensinar. Na concepção 
do autor, o conhecimento "é o 'conjunto dinâmico' de saberes e fazeres acumulado e socializado ao longo da história de cada indivíduo" (D’AMBRÓSIO, 2016, p. 287), resultado da busca de sobrevivência e transcendência e que, portanto, dá origem a técnicas e a estilos de comportamento. Com base nisso, D’Ambrósio foi conduzido ao estudo de sistemas de conhecimento em geral, levando em consideração o ciclo da geração, organização e difusão do conhecimento em diferentes grupos e explica:

[...] para compor a palavra etnomatemática utilizei as raízes tica, matema e etno para significar que há várias maneiras, técnicas, habilidades (ticas) de explicar, de entender, de lidar e de conviver com (matema) distintos contextos naturais e socioeconômicos da realidade (etnos) (D’AMBRÓSIO, 2017, p.63).

De certa forma distante, portanto, da matemática dita acadêmica, a Etnomatemática reconhece o conhecimento do outro e rompe "com o racionalismo moderno e com a unicidade nas formas de "produzir saber"” (CLARETO, 2003, p.177). A abordagem d'ambrosiana, analisa o conhecimento para além da academia e "procura pensar a cultura e a diversidade cultural para além da homogeneidade e hegemonia da cultura ocidental e para além das amarras das culturas de elite" (CLARETO, 2003, p.54), situando "o pensamento da ciência in lócus, sobre o solo fecundo da experiência humana, onde a inteligência sensível se ergue para trabalhar o mundo"(VERGANI, 2007, p.35).

No contexto em que a pesquisa se desenvolve, a dimensão política se associa à dimensão educacional da etnomatemática. Política, pois, nos coloca diante da busca por "reais possibilidades de acesso para o subordinado, para o marginalizado e para o excluído" (D’AMBROSIO, 2017, p.42), com respeito à cultura do indivíduo.

Além disso, Vergani (2007) reconhece que o potencial pedagógico da etnomatemática está em ser uma metodologia culturalmente dinâmica, com enraizamento na realidade social, uma observação vivificante das práticas comportamentais e uma ação autenticamente sócio-siginificativa. Além disso,

A educação etnomatemática é um processo antropológico que veicula todas as componentes do nosso conceito de cultura: aspectos semióticos, simbólicos e comunicacionais; aspectos sócio-políticos, de relações do trabalho, de relações com o poder; aspectos cognitivos, modos de saber; aspectos tecnológicos. (Vergani, 2007, p.34)

D’Ambrosio (2016) concretiza a ligação entre política e educação quando propõe o curriculum trivium. Segundo o autor, trata-se de "uma resposta educacional às expectativas de 
eliminação de iniquidade e violações da dignidade humana, primeiro passo para a justiça social" (p.101).

A proposta de D’Ambrosio (2016) é um caminho às estratégias de ação educativa com base no ensino crítico de três instrumentos - comunicativos (literacia), analíticos/simbólicos (materacia) e materiais (tecnoracia). A literacia diz respeito à capacidade de um indivíduo lidar com situações de seu dia a dia de forma crítica, associando as habilidades de ler e escrever à interpretação, de modo a oferecer a ele a consciência de sua humanidade e da sua autonomia.

A materacia se refere a conhecimentos matemáticos, mas não apenas os códigos e resultados em si, e sim, o conhecimento necessário para a análise simbólica. “A crítica dos códigos e resultados permite reconhecer implicações e interpretações e analisar consequências e possibilidades futuras" (D’AMBROSIO, 2016, p.110).

Para a tecnoracia, o autor define duas metas: a primeira, é sobre a responsabilidade sobre consumo de tecnologia; a segunda, sobre a responsabilidade na produção de tecnologia, englobando, assim, a "análise crítica dos objetivos, consequências, ética, história e filosofia da tecnologia" (D’AMBROSIO, 2016, p.112).

Para além da construção de um currículo, nosso interesse, na segunda etapa da pesquisa, é a aquisição e o desenvolvimento de novas competências de literacia, materacia e tecnocracia. Aqui, com inspiração no trabalho de Vieira (2013), chamamos essas competências de conhecimento trivium.

Para isso, pretendemos utilizar a proposta da investigação de temas geradores de Paulo Freire (2019) a partir de elementos obtidos na primeira etapa da pesquisa que serão apresentados no item seguinte. Tal proposta será implementada por meio ações pedagógicas que visam a compreensão crítica da realidade, as investigações em torno de temas geradores serão orientadas pelos elementos do curriculum trivium, de modo que também os conhecimentos matemáticos que circulam entre imigrantes haitianos possam ser analisados.

\section{Português para haitianos: primeiras aproximações}

No desenvolvimento da pesquisa, as primeiras aproximações se deram utilizando como metodologia a observação participante, complementando-se com registros escritos em caderno de campo. A escolha por esta metodologia se justifica considerando a afirmação de Ludke e André (1986), por possibilitar

um contato pessoal e estreito do pesquisador com o fenômeno pesquisado, [...] o observador pode recorrer aos conhecimentos e experiências pessoais como auxiliares no processo de compreensão e interpretação do fenômeno estudado (p.26). 
O objetivo da primeira fase do estudo era conhecer o contexto e a dinâmica das relações com os imigrantes haitianos. Além disso, a observação propiciou o contato com a realidade auxiliando no levantamento de elementos socioculturais que poderiam ser explorados para a compreensão das fronteiras que atravessam os imigrantes haitianos no Brasil. Além de evidenciar possíveis temas geradores a partir do convívio das realidades, colaborando para o planejamento da segunda etapa da pesquisa, pautada no conhecimento trivium.

O relato a seguir foi elaborado a partir das anotações no caderno de campo e da observação da primeira autora do texto em aulas semanais em um projeto de português para haitianos no CIEJAPerus na cidade de São Paulo.

A partir do dia 25 de março de 2018 passei $^{5}$ a frequentar o CIEJA-Perus semanalmente, observando, participando e, eventualmente, prestando algum auxílio aos estudantes e professores, nos horários denominados $5^{\circ}$ e $6^{\circ}$ períodos (das 17:30 às 19:40 e das 20:10 às 22:20, respectivamente). As três professoras que acompanhei sempre me receberam bem e me apresentaram aos estudantes como professora e pesquisadora.

No início, minha presença era vista com um certo estranhamento pelos estudantes, tanto brasileiros, quanto haitianos, mas a dinâmica das aulas permitiu com que eu me aproximasse e, em pouco tempo, o estranhamento foi se desfazendo.

Nas primeiras idas à escola, acompanhei as aulas de Língua Portuguesa, comum aos estudantes brasileiros e haitianos. Nessas aulas, cerca de um terço do total de estudantes presentes era de haitianos com níveis diferentes de fluência no idioma. Alguns se expressavam bem e, por isso, ajudavam, fazendo traduções, os que não compreendiam as instruções da professora. No entanto, de maneira geral, era possível perceber que muitos estudantes não acompanhavam as discussões da aula por conta da dificuldade de compreensão.

Seguindo com minhas idas ao CIEJA, passei a participar das aulas de História. Em uma dessas aulas, a professora abordava o tema de autobiografia a partir da construção de uma linha do tempo e pediu que cada aluno produzisse a sua. Pude auxiliar alguns estudantes, principalmente haitianos, que não haviam compreendido como executar a tarefa e, assim, foi possível conhecer algumas trajetórias de imigração.

Um deles, por exemplo, me contou que, quando tinha 17 anos, após o terremoto de 2010, foi morar na República Dominicana com um irmão para trabalhar. Depois precisou voltar ao Haiti, onde

\footnotetext{
${ }^{5}$ A primeira pessoa do singular é usada, neste item, por se tratar de relato pessoal de pesquisa da primeira autora do artigo.
} 
sua mãe havia permanecido, mas com as dificuldades que o país enfrentava, decidiu vir para o Brasil, sozinho, há quatro anos. Pegou um avião até o Panamá e, depois, outro até São Paulo, o que confirma as pesquisas sobre o fluxo Haiti-Brasil

No primeiro semestre de 2018, os professores do CIEJA perceberam a dificuldade dos estudantes haitianos em acompanhar as aulas regulares e, por isso, foi implementado o curso de Português básico para haitianos. Aqueles que tinham maior dificuldade com a língua, que estavam há pouco tempo no Brasil ou que queriam aprofundar o conhecimento, passaram a frequentar essas aulas.

A partir do mês de maio, então, passei a participar das aulas de Português para haitianos, às segundas-feiras, no horário das 17:30 às 19:40, como monitora. Nessa posição, auxiliava os estudantes nas atividades propostas pela professora e respondia muitas dúvidas sobre palavras e expressões utilizadas no cotidiano. Normalmente, queriam saber sobre o uso e significado de gírias que ouviam no local de trabalho, mas também sobre regras de escrita em Português.

Aquelas aulas se configuraram em um ambiente de encontro para os haitianos, onde eles pareciam mais livres para conversar entre si - sempre em crioulo - e para se expressar em português. A interação entre eles era, na maior parte do tempo, descontraída e permeada de muitas risadas, apesar do visível cansaço após o dia de trabalho.

$\mathrm{Na}$ aula do dia 13 de maio, sobre palavras que expressam emoções, nem todos quiseram falar sobre como se sentiam naquele momento. Embora alguns tenham declarado estarem felizes, outros exprimiram outros tipos de sentimento:

- Estou com saudade do meu pai (aluna haitiana, há 9 meses no Brasil); - Estou mal, porque penso no meu filho (aluna haitiana, há 10 meses no Brasil, um dos filhos ficou no Haiti).

Com as aulas totalmente direcionadas para a comunicação em português ficou mais fácil saber obter informações sobre os estudantes imigrantes. Por exemplo, que eles não residem próximos à escola (distrito de Perus), como eu imaginava. Muitos trabalham no bairro da Lapa ou no centro da cidade de São Paulo e moram em locais como o Morro Doce (Zona Oeste de São Paulo) ou o município de Francisco Morato.

Outro ponto a se considerar é em relação ao trabalho. Os imigrantes haitianos relataram como principal ocupação o trabalho na construção civil, como encanadores, como pintores, com limpeza, como cozinheiros. Ficou evidente a necessidade de inserção no mercado de trabalho, por exemplo, no caso de um aluno que relatou que possui formação como engenheiro civil, mas, no Brasil, precisa trabalhar como pedreiro ou ajudante de obras. Por outro lado, o desemprego vivido por alguns revelado na fala de outro aluno: "o Brasil é ruim, não tem trabalho”. Tal afirmação pode indicar, 
ainda, que havia uma expectativa relacionando a vinda para o Brasil com a possibilidade de conseguir trabalho.

Um outro aluno relatou que veio para o Brasil há cerca de 2 anos com a esposa. Foram primeiro até o Peru e, por via terrestre, chegaram em Manaus, onde tiveram o primeiro filho (me mostrou as fotos da criança pelo celular). Como em Manaus, segundo ele, era muito difícil conseguir trabalho, veio para São Paulo.

Estar em contato com esse grupo de haitianos me fez perceber que o "ser haitiano" é algo que os une. No entanto, as histórias de vida são variadas e, portanto, a experiência vivida por cada um é diferente.

Além disso, pude constatar pelos assuntos que circulam entre os haitianos, que, de fato, o trabalho é uma de suas grandes preocupações. Por esse motivo, acredito, com base em Freire (2019), que em um contexto educacional, com uma especificidade cultural, a "leitura" da realidade dos educandos pode partir da análise de suas práticas sociais, enquanto trabalhadores imigrantes, isto é, tendo o trabalho como um "tema gerador".

A partir do levantamento do tema gerador, iniciaremos o desenvolvimento da segunda etapa do projeto. A proposta é deslocar a metodologia da observação participante para a investigação-ação, promovendo ações pedagógicas centradas nas competências de literacia, materacia e tecnoracia, no contexto de ensino de Português para haitianos.

\section{Considerações ou estar "em fronteiras"}

A realização da primeira etapa desta pesquisa teve como principal motivação a aproximação com a realidade de estudantes imigrantes haitianos que se encontram no CIEJA-Perus, na cidade de São Paulo, com o propósito de aprender português.

Para isso, iniciamos a investigação buscando dados sobre o fluxo migratório de haitianos para o Brasil. Em seguida, por meio da observação participante, pudemos nos aproximar do contexto de estudo e levantar elementos sobre a realidade dos haitianos no Brasil, a partir de experiências pessoais.

A realidade que percebemos reafirma o que discutimos sobre fronteiras. O Haiti é um dos países mais pobres no mundo, os haitianos que migram, projetam uma vida melhor em outro país. No processo de migração, como vimos, são inúmeras as dificuldades para atravessar as fronteiras de um país para o outro. Ao chegar no destino, permanecem em fronteiras, sociais e culturais, quando encontram dificuldades de comunicação por causa do idioma, quando ficam fora do mercado de trabalho, quando enfrentam o preconceito dos moradores locais. 
Os haitianos ocupam o mercado de trabalho informal, vivenciando experiências diaspóricas em fronteiras políticas, sociais e culturais. $\mathrm{O}$ fato de estarem nesse espaço de invisibilidade carrega ainda a dificuldade com o idioma e as condições precarizadas - trabalhando e vivendo nas periferias das cidades - e, lamentavelmente, o racismo.

O projeto de português para haitianos do CIEJA-Perus na cidade de São Paulo pode ser visto como uma ação afirmativa de acolhimento aos haitianos, com sua identidade e cultura. Esperamos com a proposta de implementação da ação pedagógica baseada no conhecimento trivium, agregar práticas culturais desses estudantes, de modo a contribuir para a circulação de saberes do cotidiano no tema gerador trabalho envolvendo a materacia, literacia e tecnoracia.

\section{Referências}

BALIBAR, E. Politics and other scene. Verso, 2002.

CLARETO, S. M. Terceiras margens: um estudo etnomatemático de espacialidades em Laranjal do Jari (Amapá). Tese (doutorado) - Universidade Estadual Paulista, Instituto de Geociências e Ciências Exatas. Rio Claro, 2003.

FERNANDES, D.; FARIAS, A. V. A diáspora haitiana no Brasil: processo de entrada, características e perfil. In: BAENINGER et al. (orgs.). Migração Haitiana no Brasil. Jundiaí: Paco Editorial, 2016. pp. 95-111.

FREIRE, P. Cartas à Guiné-Bissau: registros de uma experiência em processo. São Paulo: Editora Paz e Terra, 2011.

FREIRE, P. Pedagogia do oprimido. São Paulo: Editora Paz e Terra, 2019.

HANNERZ, U. Fluxos, fronteiras, híbridos: palavras-chave da antropologia transnacional. Mana [online], vol.3, n.1, pp.7-39, 1997. Disponível em: https://www.scielo.br/pdf/mana/v3n1/2454.pdf. Acesso em: 18 ago. 2020.

MARTINS, J. S. Fronteira: a degradação do outro nos confins do humano. São Paulo: Contexto, 2019.

MESQUITA, M. Fronteiras Urbanas - Sobre a humanização do espaço. In: MESQUITA, M. (org), Fronteiras urbanas: Ensaios sobre a humanização do espaço. Viseu: Anonymage, 2014. pp. 19-31.

MOREL, M. A Revolução do Haiti e o Brasil escravista: o que não deve ser dito. 1. ed. Jundiaí, SP: Paco Editorial, 2017.

OBMIGRA. Relatório Anual 2019. Série Migrações. Brasília, DF: Obmigra, 2019.

Disponível em: https://portaldeimigracao.mj.gov.br/pt/dados/relatorios-a. Acesso em: 1 nov. 2019.

RIBEIRO, C. A. Apresentação. In: CÉSAIRE, A. Discurso sobre o colonialismo. Tradução de Anísio Garcez Homem. Florianópolis, SC: Letras Contemporâneas, 2010. 
eISSN: $2526-9062$

SANTOS, Boaventura de Sousa. Para além do pensamento abissal: das linhas globais a uma ecologia de saberes. In: SANTOS, Boaventura de Sousa, MENESES, Maria Paula (orgs.). Epistemologias do sul. São Paulo: Cortez, 2010.

SEGUY, F. A catástrofe de janeiro de 2010, a "Internacional Comunitária" e a recolonização do Haiti. Tese (Doutorado em Sociologia) - Instituto de Filosofia e Ciências Humanas da Faculdade de Campinas. Campinas, SP, 2014.

VIEIRA, N. M. C. Os tempos que o tempo tem: o conhecimento trivium dos professores de Matemática em período de mudança. Tese (Doutorado). Instituto de Educação da Universidade Lusófona de Humanidades e Tecnologias. Lisboa, 2013.

VERGANI, T. Educação Etnomatemática: o que é? Natal: Flecha do Tempo, 2007.

VILLEN, P. Periféricos na periferia. In: BAENINGER et al. (orgs.). Migração Haitiana no Brasil. Jundiaí: Paco Editorial, 2016. pp. 45-64.

WENDEN, C. W. As novas migrações. SUR 23, v.13, n.23, pp.17 - 28, 2016. Disponível em: https://www.sur.conectas.org/wp-content/uploads/2016/09/1-sur-23-portugues-catherine-wihtol-dewenden.pdf. Acesso em: 17 jul. 2020. 